\title{
Opacity of Character: Virtue Ethics and the Legal Admissibility of Character Evidence
}

\author{
Jacob Smith and Georgi Gardiner \\ University of Tennessee \\ Draft, to appear in Philosophical Issues 31 (2021)
}

\begin{abstract}
Many jurisdictions prohibit or severely restrict the use of evidence about a defendant's character to prove legal culpability. Situationists, who argue that conduct is largely determined by situational features rather than character, can easily defend this prohibition. According to situationism, character evidence is misleading or paltry evidence.

But proscriptions on character evidence seem harder to justify on virtue ethical accounts. It appears that excluding character evidence either denies the centrality of character for explaining conduct-the situationist position—or omits probative evidence. Situationism, after all, is antithetical to virtue ethics.

This essay provides a virtue ethical defense of character evidence exclusion rules. We show that existing virtue ethical rebuttals to situationism themselves support prohibitions on character evidence; even if behavior arises from stable character traits, character evidence should be prohibited. In building our case, we provide a taxonomy of kinds of character judgment and reconcile the ubiquity and reasonableness of character judgements in ordinary life with the epistemic legitimacy of character evidence prohibitions in law.
\end{abstract}

\section{Keywords:}

Situationism, virtue ethics, character traits, conduct, character evidence law, Federal Rules of Evidence, FRE 404(a), structure of character judgments.

\section{Introduction}

Evidence law governs when and how evidence can be adduced during legal procedures. The rules governing character evidence are a particularly contentious and epistemically rich facet of evidence law. Regulated uses of character evidence includes appealing to the defendant's personality, dispositions, or prior conduct to suggest they performed a particular action on a specific occasion. Suppose the prosecution claims the defendant is a reckless and irresponsible driver, for example, to suggest he drove recklessly during the contested incident. This qualifies as character evidence because claims about the defendant's personality are used as evidence that he committed a particular action. In many jurisdictions, including the US, use of such reasoning to prove culpability is largely proscribed.

These prohibitions seem epistemically dubious. Reasoning with character judgments is ubiquitous in everyday life. Such assessments guide decisions about who to hire, who to cultivate friendships with, and who to distrust. We can often predict who will appreciate a pun, and who will groan. Spotless records can lower car insurance premiums. Good teachers modulate their teaching style and level to suit individual students. This requires character evidence, and such evidence is deemed reliable and necessary for ordinary life.

Epistemic aims are central to the legal system: legal procedures aim to present relevant evidence and assess whether that evidence establishes contested claims to a particular standard of proof. Excluding relevant evidence conflicts with these epistemic aims and, accordingly, relevant evidence is generally 
admissible. ${ }^{1}$ Given its ubiquity, reasoning from character to action—and from actions to characterseems reliable and informative. Excluding character evidence plausibly leads to verdicts that are less accurate and less evidentially well-grounded. Perhaps character evidence exclusions are justified by moral or political considerations, the thought continues, but they are epistemologically suspect.

As we describe below, epistemological concerns about character evidence exclusions are particularly acute for virtue ethicists. Virtue theory emphasizes the centrality of character for explaining and governing conduct. There is apparent tension between this and endorsing prohibitions on character evidence for legal factfinding. Virtue ethics thus faces a challenge: Can it motivate the epistemological legitimacy of excluding character evidence from legal factfinding, or must it concede that character evidence is probative and can only be excluded on non-epistemic grounds?

In what follows we first sketch the relevant character evidence exclusion rule. Section two describes situationism, the view that conduct is largely determined by situational features, rather than a person's character. And we sketch how situationism is marshalled against virtue ethics. Section three explains how situationism can vindicate legal character evidence prohibitions; according to situationism, character evidence is misleading or paltry. We then sketch why virtue ethics, by contrast, appears committed to the probative value of character evidence in law, and why this conclusion is uncomfortable. Against this, sections four and five show that virtue ethics itself explains why character evidence prohibitions are epistemically justified.

Section four describes four families of virtue ethical rebuttals to situationism. These are the rarity responses, conflicting traits responses, narrow traits responses, and reasons-centering responses. Section five argues that these virtue ethical responses to situationism themselves entail that character evidence is abstruse: Inferences from character to conduct are evidentially demanding and liable to mislead. To do this, we first develop a taxonomy of kinds of character judgment. We then draw out the epistemological implications of the four families of responses sketched in section four. Our discussion indicates that virtue ethics supports legal character evidence prohibitions, and it does so on epistemological grounds.

We conclude, in section six, by highlighting why character evidence should be excluded, even though other recondite and technical evidence is admissible. And, finally, why character evidence should be prohibited in legal contexts even if character judgments are ubiquitous in ordinary life.

The Federal Rules of Evidence (FRE) govern uses of evidence in U.S. criminal and civil cases. FRE \$404(a) states that “Evidence of a person's character or character trait is not admissible to prove that on a particular occasion the person acted in accordance with the character or trait." It thereby restricts uses of character evidence for proving conduct, including conduct of victims, plaintiffs, defendants, and others. Subsidiary rules offer exceptions to the exclusion, such as witness impeachment and inferences in criminal procedures from the decedent's bellicosity to the conclusion that they initiated the fatal combat. Note that it is kinds of inference, not kinds of evidence, that are prohibited. Our essay focuses on FRE $\$ 404$, but our virtue theoretic defense of character evidence prohibitions bears on various uses of character evidence throughout the law, such as adducing characterological evidence to cast doubt on the veracity of witness testimony.

1 Some relevant evidence is inadmissible. In the US this includes hearsay, for example, and evidence obtained through an illegal search. 


\section{Character and Conduct: The Situationist Challenge}

Character seems central to human life. In ordinary understanding, an individual's personality plays significant roles in shaping who their friends are, what they enjoy, and how they respond to circumstances. Indeed, character seems crucial for determining how people think, feel, behave, and interpret their environment. It is no surprise that character-centered theories, which emphasize the roles of stable, enduring personality traits in determining and explaining action, dominated early psychology; they reflect common sense. Gordan Allport's influential trait theory, for example, posited that personality comprises traits, and these determine behaviour. ${ }^{2}$ Allport (1937: 295) writes that personality traits "render many stimuli functionally equivalent... [and] initiate and guide consistent (equivalent) forms of adaptive and expressive behavior."

Empirical social psychology later attempted to dethrone character as the central explanation of conduct. In an early and influential study, Hartshorne and May (1928) investigated honesty in schoolchildren, including whether they lied, cheated, and stole across various contexts. Hartshorne and May claimed that whether the same individual acted honestly varied by type of conduct and by context. They concluded that honesty was not a unified and influential character trait.

These situation-centered ideas gained traction, culminating in the advent of situationism in social psychology. Situationism holds that behavior is determined by external, contingent, seemingly incidental, or normatively irrelevant features of the person's situation, rather than their internal stable dispositions. Determining whether character traits or situations are more influential in determining behavior is known as the person-situation debate in psychology. ${ }^{3}$

We sketch two studies that vividly motivated situationism, John Darley and Daniel Batson's 1973 Good Samaritan experiments and Stanley Milgram's 1961 experiments on obedience to authority. The Good Samaritan experiments tested subjects' willingness to aid a stranger in apparent distress. Seminary students were instructed to walk to another building to deliver a lecture. Two variables were adjusted: Whether the lecture was about seminary jobs or the Good Samaritan parable, and whether participants were told they had spare time, were on time, or were late. On route, they passed a confederate who, slumping in an alleyway, moaned and coughed in apparent medical distress. Darley and Batson report that helping correlated only with not feeling rushed; no significant effect was found for characterological features or assigned lecture topic. ${ }^{4}$

The infamous Milgram experiments tested subjects' willingness to obey authority, even at the cost of harming others. Participants were assigned "teacher" roles, whilst confederates were assigned "learner" roles. Participants believed the roles were distributed randomly. The participants asked the learners questions and were instructed to administer increasingly large electric shocks if the answers were incorrect. The confederates appeared to be in increasing pain. Unbeknownst to the participants, the confederates were merely acting, and no electric shocks were administered. Milgram thought that participants who were even minimally motivated by traits like compassion would avoid administering

\footnotetext{
Situationism therefore challenges the positions of trait theorists, such as Cattell (1950) and Eysenck (1953).

Ross and Nisbet (1991).

$40 \%$ of the participants offered some help. 10\% who were hurrying stopped to help, compared to $45 \%$ of those in a moderate rush, and 63\% of those in no rush (Darley and Batson, 1973: 105).
} 
the shocks. However, the majority of participants obeyed the commands even when the shocks appeared potentially lethal. ${ }^{5}$

Such results motivate situationism. ${ }^{6}$ This is because they putatively reveal that character plays a relatively small role in determining conduct, relative to situational features. The assumption is that if characterological traits steered the ship, the observed conduct would be different. If conduct stemmed from character, the situationists hold, we would expect people to help the confederate in apparent distress. Or, at least, whether the participants did so would be sensitive to characterological features, such as whether they are currently reflecting on the Good Samaritan parable, rather than situational features, such as running late. Similarly situationism holds, if virtue theory is true, people would act from broad dispositions to avoid harming others, rather than situational features, such as scientists' instructions. A background assumption is that virtues are not wholly uncommon, at least amongst seminarians or when the relevant virtues are minimal, such as those that prevent authoring severe gratuitous harm.

Gilbert Harman, John Doris, and others marshal situationism against virtue ethics. They argue virtue ethics posits character traits with particular features, and that empirical psychology reveals that such traits either do not exist or are extremely rare. As Alfano (2012: 225) writes,

Virtue ethicists have empirical skin in the game: if virtue ethics is explanatory, then the virtues had better be psychologically real. What philosophical situationists argue, however, is that most people do not possess traits that resemble the virtues as traditionally conceived.

Harman (1999: 317) describes this orthodox conception of character traits as "relatively long-term stable disposition[s] to act in distinctive ways. An honest person is disposed to act honestly. A kind person is disposed to act kindly." That is, virtues endure and reliably lead to trait-relevant actions across a range of trait-relevant contexts. At least, the contexts are trait-relevant as the agent perceives them; we return to this in section 5.5. Alfano claims that positing character traits should "support counterfactuals and confident predictions" about how a person will behave. ${ }^{7}$ And most situationists hold the character traits posited by virtue ethics are broad, rather than narrow. It includes honesty, for example, rather than honesty-concerning-written-tests and honesty-concerning-oral-tests. Situationist critiques of virtue ethics typically hold that the virtues posited by philosophical virtue ethics map onto the psychological posits of traits. Impugning trait theory in psychology thereby threatens virtue ethics in philosophy. ${ }^{8}$

5 The shock magnitudes ranged from 15 to 450 volts. The former was labeled "slight shock" while the latter was labeled "danger: severe shock" and embellished with a skull symbol (Milgram 1963: 372). 14 out of 40 participants ended their participation after administering the 300 volts shock. The remaining 26 administered the possibly lethal 450 volts.

6 Situationism was later bolstered by experiments purporting that conduct is largely determined by seemingly irrelevant background conditions, such as odor (Barron, 1997), light (Zhong et al., 2010), and ambient noise (Matthews and Cannon, 1975; Cohen, 1978).

7 Alfano (2012: 231-2).

8 Alfano (2013). Alfano (2012; 2013) extends the situationist critique of virtue ethics to virtue epistemology. 


\section{Character Evidence Prohibitions: Situationism and Virtue Ethics}

The situationist critique of virtue theory leverages experimental results against a philosophical theory. But situationism, if true, also threatens ordinary epistemic conduct. We noted above that character judgments are ubiquitous. We attribute character traits to individuals and use those attributions to explain and predict behavior. If situationism is true, such judgments are largely unjustified.

Recall legal character evidence prohibitions, such as FRE 404(a):

FRE $\int 404$ (a) Evidence of a person's character or character trait is not admissible to prove that on a particular occasion the person acted in accordance with the character or trait.

We noted above that character evidence exclusions like these seem epistemically dubious. ${ }^{9}$ They proscribe relevant evidence, which impedes epistemic aims of legal factfinding, such as reaching accurate, evidentially-supported verdicts. If character ascriptions are reliable indicators of conduct, then FRE 404(a) can only be justified on moral or political grounds; it remains epistemologically indefensible. ${ }^{10}$

Situationism provides an epistemic justification for character evidence exclusions. If situationism is correct, character ascriptions yield poor evidence about conduct on the contested occasion. Unaware of situationism, factfinders speciously consider character judgments reliable, and so overestimate their probative force. Character evidence leads factfinders astray and so should be excluded on epistemic grounds.

Miguel Méndez, who marshals situationism to defend FRE 404(a), writes: ${ }^{11}$

If, as [the early situationist studies] found in the sixties, even trivial situational differences may reduce the expected correspondence or correlation [amongst intuitively concomitant behaviours such as cheating clients in the sale of goods and cheating on taxes] to zero, then the law was justified in banning the use of predisposition evidence. [According to such studies] consciously cheating clients on sales probably would tell us nothing about whether the defendant consciously understated his income or overstated his deductions.

In a similar vein, David Sonenshein (2011) leverages situationism to excoriate permitted uses of prior acts evidence. Sonenshein's target is 404(b)(2), which permits evidence of a person's prior acts to help prove intent. He considers this propensity evidence - that is, character evidence-and so undermined by situationism. He writes,

9 For critical discussion, see Tillers (1998); Melilli (1998: 1565-1577); Laudan (2016: 138-141). For a survey, see Gardiner (2019).

10 Things are a little more complicated. Legal uses of character evidence are often infected by racist biases (Thompson, 2015; Armour, 1994; Ulliver, 1982). Even if the overall accuracy rate is increased by admitting character evidence, the distribution of error can constitute both a moral and epistemic consideration against permitting character evidence for legal factfinding. But one strength of our argument against legal uses of character evidence is that it does not hinge on disparate impacts or effects of bias.

11 Méndez (1996: 234). Méndez's language echoes that of Walter Mischel—an early proponent of situationism—who writes: "Individuals show far less cross-situational consistency in their behavior than has been assumed by trait-state theories. [...] Even seemingly trivial situational differences may reduce correlations to zero" (Mischel, 1968: 77). 
Under the discredited trait theory, the fact that an individual previously robbed $\mathrm{X}$ should be admitted under 404(b) in a subsequent trial for robbery of $\mathrm{Y}$ on the issue of intent to rob. [...] To state an individual is disposed to a certain action, say murder, rejects all rules of science and common sense.

Most social scientists, agree that it is impossible to infer intent from one crime to another absent some inextricable link between them [...] Making any correlation between past behavior or intent and future behavior or intent requires a significant expert psychological study of the person involved and the specifics of the situation in order to more specifically define behavior dispositions. Clearly, simply demonstrating the defendant has, in the past, had the intent to kill by offering similar crimes evidence under 404(b) does not qualify as an expert psychological study. The practice of admitting such evidence continues to rest solely on the archaic "trait theory" and fails as a matter of logical relevance. (Sonenshein, 2011: 256-7)

Méndez and Sonenshein emphasize that, if situationism is true, judgments from character to conduct are unreliable and-if they could be epistemically responsible-require vast amounts of background information about both the individual and nuanced, contingent, apparently irrelevant situational details. According to situationism, then, character judgments are liable to mislead and should be prohibited.

But what about virtue ethicists? How should virtue ethics view character evidence exclusion rules, like FRE 404(a)? On the one hand, virtue ethics centers character in explanations of the normative landscape. There is apparent tension between this and opposing uses of character evidence in legal factfinding. And, recall, character judgments are commonplace in everyday life. Given this ubiquity, if the main opposition to the epistemic pedigree of such judgments stems from situationism - the very antithesis of virtue ethics - it seems natural that virtue ethics would be sanguine about the reliability of character judgments in both legal and non-legal contexts.

On the other hand, using character evidence for legal findings of culpability seems morally suspect. Studies suggest it is prejudicial, disproportionately disadvantages defendants from marginalized groups, and that unfavorable character evidence is "more salient and had a greater impact on jurors than [...] favorable [character] evidence." ${ }^{, 12}$ Jurors also systematically overestimate its evidential force. ${ }^{13}$ Ventilating prior misconduct and unfavorable character traits can be unfair because it distracts from the question under investigation. A jury might find a defendant guilty simply in response to former crimes, for example, without paying due attention to whether the particular crime is proven beyond reasonable doubt. And a central tenet in many jurisdictions is that trials judge the action, not the defendant.

Put another way, it appears that excluding character evidence either denies the centrality of character for explaining conduct - the situationist position_or omits probative evidence. The widespread opposition to using character evidence to prove guilt raises the question of whether resources of virtue ethics can themselves cast doubt on the epistemological legitimacy of character evidence. That is, can

12 Lupfer et al (1986).

13 Sanchirico (2001: 1244). 
virtue ethics itself epistemologically motivate FRE 404(a), and similar character evidence prohibitions in legal factfinding?

In what follows we develop a virtue theoretic defense of FRE 404(a). We argue it is justified on epistemological grounds. We do this by examining the epistemological contours of character judgments and the epistemological implications of existing virtue ethical responses to the situationist critique.

We first outline four influential families of rebuttals to situationism. We then consider their epistemological consequences. The first two, the rarity response and the conflicting traits response, argue the results of the situationist experiments are compatible with virtue ethics, even if situationists are correct that the kinds of traits investigated by the psychological studies match the traits posited by virtue ethics. The latter two, the narrow traits response and the reasons-centering response, challenge the assumption that the empirical studies investigate the same kind of thing as the character virtues posited by virtue ethics. They thereby accuse situationism of missing the target.

Note that although we call them "responses", they are best understood as four families of responses. Secondly, the responses are compatible. Indeed, they are mutually supporting. Thirdly, they are not exhaustive of virtue ethical rebuttals to the situationist critique, and virtue ethicists also identify methodological inadequacies of the studies including, in several cases, failures to replicate. ${ }^{14}$

\section{Virtue Ethical Responses to Situationism}

A Stoic aphorism holds that the sage is a rare as the phoenix. "Sophos, translated here as "sage", means a "virtuous person". ${ }^{15}$ Similarly Plato notes, "the very good and the very wicked are both quite rare, and [...] most men are between those extremes", and Aristotle concurs: "Hence also it is no easy task to be good [...] anyone can get angry-that is easy-or give or spend money; but to do this to the right person, to the right extent, at the right time, with the right aim, and in the right way, that is not for everyone, nor is it easy; that is why goodness is both rare and laudable and noble. ${ }^{16}$

These ancient virtue theorists characterize the process of becoming habituated in virtue as arduous, requiring consistent reflection on one's actions and motivations. They hold that virtue-or at least, fully virtuous people_-are scarce. If correct, the empirical results do not threaten virtue ethics. They instead affirm the rarity of virtue. As Christian Miller (2003: 371) writes, "It seems reasonable to think that we should focus on the [subjects'] internal dispositions in order to predict the outcome of this experiment only if we had strong antecedent reasons for believing that a majority of the test subjects possessed the relevant global character traits". Absent reason for thinking test subjects possess robust global dispositions like compassion, the subjects' failure to act compassionately is unsurprising. Similarly Rachana Kamtekar (2004: 473) exemplifies the rarity response to the situationist challenge when she writes, "Perhaps, however, the point of the experiment is to show that all the seminarians

14 See, for example, Kamtekar (2004: 446, 473); Miller (2004). For discussion, see Doris (2002, p 180 n 4); Alfano (2018).

15 One source for the aphorism is Seneca, Moral Letters to Lucilius Letter 42: "For one of the first class perhaps springs into existence, like the phoenix, only once in five hundred years" (Seneca, 1917: 279).

16 Plato Phaedo 89e-90a; Aristotle (1999: 1152a30-34, 1180a1-6). We are grateful to Clerk Shaw for his scholarly assistance about ancient conceptions of virtue. The prevalence of virtue depends on whether and how virtue admits of degrees. 
are just like ordinary people in that their performance or non-performance of good works is influenced primarily by how much time they have". ${ }^{17}$

Advocates of the rarity response can maintain that virtue is central to understanding when and why persons and behavior are good. Even if virtues are rare, virtue structures how we should act, who we should strive to be, and why virtue's scarcity is lamentable. The explanatory import of virtue does not entail that virtues are common or easily won.

Recall the situationist assumption that if subjects possess the relevant virtue, and character plays a significant role in shaping action, different conduct would be observed. Conflicting traits responses deny this. In response to the Milgram experiments, for example, Kamtekar (2004: 473) asks, "[W] hat if people have more than one character trait; what if they have, in addition to an aversion to cruelty, a disposition to obedience or to cooperativeness?" That is, she asks whether alternative traits, rather than wholly situational features, underwrite the observed behavior. In this case, different traits elicit conflicting responses; the experimental conditions elicit rivalry amongst the virtues. Indeed, they are designed to do so. Similarly, Gopal Sreenivasan (2002: 60) notes "It does not follow that a failure to help someone in distress always contra-indicates compassion"; he claims the demands of one virtuous trait can conflict with those of another. ${ }^{18}$ Conflicting traits responses acknowledge the participant's conduct conflicts with the trait investigated, but hold that characterological traits are still central to the explanation of conduct.

The third family of replies - narrow trait responses — argue that ethical virtues differ from what trait theorists in psychology mean by "trait", and so deploying psychological situationism against philosophical virtue ethics misses the target. Recall that Allport understands personality traits as dispositions that render many different stimuli functionally equivalent, such that behavior remains consistent across different situations. Harman similarly emphasizes the putative uniformity of conduct produced by specific character traits. He writes,

An honest person is disposed to act honestly. A kind person is disposed to act kindly [...] Finding a wallet on the sidewalk, an honest person tries to locate the owner, whereas a dishonest person pockets the contents and throws the rest of the wallet away. How a stranger reacts to you depends whether the stranger is basically friendly or unfriendly.

[... For two people] to have different character traits, they must be disposed to act differently in the same circumstances (as they perceive those circumstances). Furthermore, character traits are broad based dispositions [to act]. Narrow dispositions do not count. (Harman, 1999: 317-318). Two paragraph breaks omitted.)

But Harman's discussion understates the variety of responses the same virtue and situation might elicit. An honest person might instead donate the money, for example, or leave it in the hopes that the owner returns. Similarly, contra Harman, two people can have different traits, and yet be disposed to act the same way. Confessing to a crime might stem from dispositions of honesty, loyalty, obedience, recklessness, or fearfulness, for example. His supervenience claim is false.

17 Indeed seminarians might be less virtuous than average, or be more concerned with virtues like punctuality or generating the right frame of mind before public presentations.

18 Sreenivasan holds that the virtues are not strongly unified (2002: 63). 
By contrast to Harman's emphasis on broad traits that reliably produce specific and distinctive conduct, Kamtekar holds that ethical virtues instead correspond to narrow actional dispositions. She notes three different facets of honesty. "[F]irst a disposition not to lie, supported by the thought that respecting others requires that one tell the truth; the second a disposition not to cheat, on the grounds that cheating exploits a system that one should uphold; and the third disposition not to steal for the reason that people should be able to enjoy secure possession of their property" (2004: 469). Someone with an honest disposition concerning lying and someone with an honest disposition concerning cheating might exhibit different behaviors in the same situation; yet both act in accord with honest dispositions to act honestly.

According to the narrow traits view, the situationists' taxonomy of traits is too coarse-grained. Virtues guide action in a good life, and so the virtuous person perceives distinctions among reasons to not lie and to not steal, and can discern differences between stealing from individuals and from corporations. They might typically avoid all these behaviors, but moral reasons can diverge in some situations, perhaps especially in experimental conditions. What the situationist interprets as behavioral inconsistency might instead be acting in accordance with finely-tuned "narrow trait" virtues.

A fourth family of virtue ethical responses to the situationist challenge claim the psychological studies - and accordingly the situationist critique of virtue ethics - focus on observed actions, but virtue ethics foregrounds the reasons for which a person acts. Exemplifying a reason-centering response, Julia Annas (2003: 25) writes, ${ }^{19}$

The virtuous agent doesn't just do the right thing, she does it for the right reason-because she understands that this is the right thing to do. And she does this dispositionally- she has a character such that she understands on each occasion what the right thing to do is.

Annas (2003: 55-6 two-page range?) considers the situationist challenge, and concludes:

[E]xploring the attacks made on virtue ethics by the situationists turns out to show how deep goes the idea that having a virtue is having, and acting on, reasons that are operative across your life overall.

[...] Virtue ethics, then, has no need to fear modern social psychology. It can go further, welcoming and making use of its findings. It has to insist, however, that social psychologists interpret virtue properly — not just as a causal explanation of behaviour but as a disposition to act on reasons that hold across one's character as a whole, a disposition which needs reference to these reasons as well as to behaviour if we are to understand it. (Emphasis added.)

Annas thus suggests situationist experiments measure the wrong thing. They do not impugn virtue ethics because they do not adequately test the reasons for which a person acts.

Psychology's person-situation debate begun to coalesce-and convalesce-around a middle ground that acknowledges the roles of both situation and character in determining action. ${ }^{20}$ These compatibilist, third-way positions, such as Walter Mischel and Yuichi Shoda (1995)'s cognitiveaffective personality system (CAPS) approach, emphasize the roles of a person's reasons for acting

19 Sreenivasan (2002) also highlights the importance to virtue ethics of a person's reasons for acting.

20 Fleeson and Noftle (2009). See Alfano (2013: 78-79) for situationist objections to the CAPS model. 
and, importantly, how a person interprets the action-relevant features of a situation. Reasons play at least two central characterological roles: How a person notices, assesses, and responds to reasons is partially constitutive of their character, and reasons interface between character and situation.

These virtue ethical responses to the situationist critique are compatible. Indeed, the responses are concordant and interlaced. Connections include that if fully virtuous persons are rare, then most people might instead exhibit narrow or conflicting virtuous traits. Virtuous development, which is the prevalent condition if full attainment is uncommon, tends towards forming increasingly broad and more unified virtues. Seneca's and Aristotle's arguments for the scarcity of virtue highlight the demanding cognitive conditions for full virtue; they hold that virtue requires deep sensitivity to, and reflection on reasons. And if virtue requires sensitivity to the reasons presented in a context thensince reasons are nuanced, multi-faceted, and varied-we might accordingly expect virtuous traits to be narrow rather than broad, and to sometimes elicit conflicting conduct.

\section{The Abstruseness of Character Evidence}

Virtue ethics emphasizes the paramountcy of virtue in moral life and holds that character is central for explaining action. Given this, one might assume characters are typically easily discerned and inferences from character to conduct are relatively well-grounded. ${ }^{21}$ Virtue theorists should correspondingly regard character evidence as epistemically valuable. Prohibitions on character evidence in legal factfinding, if justified, must be justified on non-epistemological grounds. We disagree.

This section argues that even if character traits underwrite action, character evidence is abstruse, especially when employed to help prove particular instances of conduct. We first outline the epistemological structure of character judgments. We then show that virtue theoretic responses to situationism themselves yield epistemological grounds for character evidence exclusions like FRE 404(a).

\section{i. The Structure of Character Judgment}

Character judgments include two distinct kinds. The first, character ascriptions, infers that a person has a particular character trait. We might infer a person is selfish, for example, from observing selfish conduct. Or we might ascribe selfishness from reasoning about their other traits, judgments, or values. We might hear testimony that they are selfish or infer selfishness from their general reputation. Or one might infer someone is selfish from the belief that everyone is selfish. Whatever the inputwhether well-grounded or not-the output is a character ascription: The person is selfish, honest, loving, insightful, entertaining, kind to children, and so on.

The second kind of character judgment is inferences from character ascriptions to conduct. Suppose Jill considers Dan a reckless, selfish, irresponsible libertine, for example. She might conclude from this character assessment that Dan drink drives. Ascription-to-conduct character judgments fall into two categories: Inferences to general patterns of conduct and inferences to specific instances. That is, Jill might infer that Dan sometimes drives drunk or that he drove drunk on a particular unobserved instance, past or future. As we will see, these two species of ascription-to-conduct judgment are epistemically very different, and the distinction matters for evidence law.

21 Some traits, such as some species of manipulativeness or deceptiveness, are characteristically difficult to detect. 
Note that both kinds of ascription-to-conduct judgment rely on antecedent character ascriptions; if character ascription judgments are unreliable, this infects judgments from those ascriptions to conduct. $^{22}$ Note too that character ascriptions, ascription-to-conduct-pattern judgments, and ascription-to-conduct-instance judgments interact. We might notice and categorize an action as an instance of driving fast because we antecedently consider the driver reckless, for example.

A second key distinction concerning character judgments contrasts the aims of determining facts and assessing coherence. We call the first aim the "discovery mode"; it inquires about what facts obtain. Is the person honest? Who keyed the car? Discovery mode judgments might concern the past, present, or future. They can be about specific behavioral instances, general trends, or character traits. Thus we might suspect Dan drove drunk last night, decide Lily probably owns an iron, or anticipate that Lucy will become self-centered. These are all discovery mode judgments. Inquiries need not aim for certainty or conclusiveness to qualify, but they aim to make a determination-perhaps hedged—about how the world is. Estimations, predictions and postdictions are in the discovery mode. Legal verdicts operate in the discovery mode, but it is common in everyday contexts too. Note that we do not use the term "discovery" in the legal sense of a phase of formal mutual disclosure of known facts of a case by legal adversaries. Other notions relating to the discovery mode include adjudicating, establishing, ascertaining, discerning, detecting, uncovering, and finding out.

Coherence assessments, by contrast, concern whether a proposition fits with other claims. We might say it is strange that Lily lacks an iron, given her professional attire; it makes sense if Laurie keyed the car, since he detests the owner, and if Luca were shy that would explain his silence. In the coherenceassessing mode, we might not aim to uncover any facts about the world. We instead aim to explain conduct, or render it intelligible, better understand a person, or simply see things as "making sense". We might already know who keyed the car or be unable to learn. We can assess coherence among fully hypothetical or counterfactual claims, mere suppositions, wholly resolved cases, or fictional examples. We might—and often do-criticize a film by commenting that the leading lady's attraction to the protagonist didn't fit their personalities. A mystery novel's denouement might be unsatisfactory because the plot fails hang together. Such observations might assess coherence without thereby aiming to discern further facts about the fiction or creator.

For this essay, we can set aside many nuanced details of the distinctions, including whether either discovery or coherence judgments reduce to the other. ${ }^{23}$ Even if coherence judgments are a kind of discovery judgment, for example, they exhibit distinctive epistemic features. These distinctions all cut across each other. We engage both the discovery and coherence modes for all the kinds of character judgment, for example. This yields many species of character judgment, each with importantly different epistemic properties. FRE 404(a) prohibits a particular kind of character inference: ascription-to-conduct judgments about specific unobserved past instances. And crucially, since the

22 Ascriptions-to-conduct judgments can lead to reliably true conclusions even if the antecedent character ascriptions are mistaken. The conduct might be extremely common, for example. Maggie might believe all golfers are diligent and so conclude Gordon the golfer goes to bed almost every night. The conclusion about conduct is true, even if the character ascription is false.

23 Gardiner (2012) argues the coherence-making relations that are distinctive of understanding do not reduce to further beliefs. This is consistent with the claim coherence assessments ultimately reduce to discovery-mode judgments; but it suggests that coherence-forging epistemic activities differ from determinations about facts. We grant that coherence assessments are constrained by discovery-mode judgments: If coherence assessments lack any predictive or adjudicatory power, they risk being mere just-so stories, compatible with any observation. But, nonetheless, the coherence-assessing mode differs — in aims, methods, and normative contours_-from the discovery mode. 
character judgments are to help prove a case, they are in the discovery mode, not the coherence mode. ${ }^{24}$ We call these "specific action determinations".

Anticipating what follows, here is the crux: FRE 404(a) prohibits a particular use of character evidence. Virtue ethical responses to situationism indicate that those characterological inferences are epistemically demanding, at best. To be performed responsibly, one must first identify a probative and pertinent character trait, via a well-grounded character ascription judgment. One must then make a discovery-mode inference to a specific unobserved instance of conduct. Virtue ethics indicates that such judgments are evidentially onerous and often unreliable.

\section{ii. The Rarity Response}

First, recall the rarity response. If fully virtuous people are rare, then we should expect people to fall within a developmental range of virtue. Some people are more virtuous than others tout court, some are more virtuous in some ways, others more virtuous in other ways. Our characters evolve over time, and we become increasingly or decreasingly virtuous as life unfolds. Given a realistic understanding of moral development, the rarity response predicts an epistemic morass. One person is usually honest, but not unkind, another is often kind but self-absorbed. A person might exhibit uncharacteristic selfabsorption during a divorce or become self-absorbed with age. Their friend, by contrast, might grow less self-centered with age. If full virtue is rare, people's behavior is inconstant, as they act in accordance with virtue only sometimes. They might behave better if reminded of good reasons, and worse when distracted. They might be generous in some contexts, and to some people, but not others.

If full virtue is rare, we would anticipate that many people resemble Christian Miller's mixed trait account. ${ }^{25}$ Miller claims characters comprise "mixed traits" - stable dispositions to think and act in ways that could appear virtuous or vicious depending on relatively thin contingent conditions. A person with a mixed helping trait, for example, may benefact acquaintances but not strangers (Miller, 2013: 184). Or she may be inclined to help propinquitous strangers or when doing so would prevent guilt (2013: 157). On Miller's view, "morally heterogeneous" mixed traits are widespread. ${ }^{26}$ Miller claims the prevalence of mixed traits provides a virtue ethical explanation of the situationist's empirical observations. He thereby exemplifies a rarity response to the situationist critique.

The rarity response thus predicts a prevalence of narrow, conflicting, inconstant, contingent, situationspecific behavioral dispositions. Under these conditions, character evidence is abstruse. It is hard to know a person's character, and even harder to judge how character elicits conduct. Discovery-mode judgments about unobserved specific actions_- that is, specific action determinations — are particularly challenging.

Unfavorable character evidence influences jurors more than favorable character evidence. The rarity response can help explain why. The rarity response suggests that virtue ascriptions are often false. They are honorifics, compliments, or aspirational, but seldom accurately describe the recipient. ${ }^{27}$ The

24 This claim is consistent with inference to the best explanation accounts of legal factfinding. (Kaplan 1968; Eggleston 1983) Even if determinations of fact proceed — or should proceed_via judgments about best explanations, trials nonetheless aim to determine the facts; they operate in the discovery mode.

25 On Miller's view, mixed traits are stable features of characters. For our discussion, the relevant traits can be either stable or inconstant.

26 The term "morally heterogeneous" is from Westra (2020).

27 Alfano (2013) describes "factitious virtue" ascriptions, which can influence recipients' conduct to better approximate virtuous action. 
probative value of unfavorable character ascriptions might accordingly be overestimated because hearers erroneously assume that negative character traits attributed to the defendant are unalloyed and uncommon. Hearers fail to realize that similar descriptions apply to everyone in the courtroom and the defendant's traits are nuanced and morally heterogeneous.

Rarity responses indicate that virtue ascriptions are ill-suited for ascertaining specific instances of unobserved behavior. But, as noted above, they nonetheless foreground virtue in explanations. Even if full virtue is scarce, virtue ethics can explain what is good and right. When unfurling the epistemological implications of the rarity response, we noted evidential challenges stemming from the fact that characters evolve. People change. The situationist challenge focuses on a person's observed actions at a time slice. Focusing instead on a person's diachronic features is a deeply characterological re-emphasis. ${ }^{28}$

\section{iii. Conflicting Traits Responses}

We now turn to the epistemic implications of conflicting traits responses. Conflicting traits responses claim that virtuous traits compete to produce various behaviors. Accordingly the participants' apparent obedience and lack of compassion is consistent with their possessing both traits. Recall Sreenivasan (2002: 60): "It does not follow that a failure to help someone in distress always contra-indicates compassion." Given this, character ascriptions and character-to-conduct judgments are thereby more difficult. Character-to-conduct judgments about particular unobserved instances are particularly challenging, especially in the discovery mode, rather than the explanatory mode. Predicting behavior from character trait ascriptions requires not merely evidence the person has a specific trait; one also requires evidence to justify multiple other trait attributions and evidence about how those traits compete to produce action in a specific context. The conflicting traits responses thus indicate the character evidence judgments prohibited by FRE 404(a)—-that is, "specific action determinations"are epistemically burdensome and largely unreliable.

Recall Méndez's example of inferring that a defendant committed tax fraud from an alleged dishonest disposition. Without the character evidence prohibitions of FRE 404(a), the prosecution can argue that the defendant's possessing the disposition renders his guilt more probable. Given that people think of character inferences as ubiquitous and reliable in everyday life, such arguments could be persuasive in legal contexts. (Section six casts doubt on their prevalence and reliability in everyday life.) But given the conflicting traits response, evidence of a dishonest disposition does not suffice to indicate a propensity for specific actions like tax fraud; one must also have evidence about how this trait competes with other traits, such as caution or fearfulness, and which behavioral dispositions would surface in a given context, from the defendant's broader nexus of competing traits.

This is evidentially burdensome and might be impossible in the evidentially-constrained context of a courtroom. Even if we can know close friends this well, factfinders cannot typically learn so much about a defendant. Indeed, it might require scientific expertise about character traits. Since people ordinarily think of character evidence as reliable, it can lead factfinders astray.

To emphasize: In the courtroom, a particular instance is investigated. The inference must be to specific instances of conduct, not to general behavioral patterns. Character evidence might lead a friend to think the defendant sometimes acts dishonesty, but legal factfinders must determine whether the defendant acted dishonestly on a specific unobserved occasion. These specific action determinations

28 Annas (2003) also emphasizes character growth in her discussion of the situationist challenge to virtue ethics. 
are evidentially onerous, especially since traits can conflict. The factfinder must assess how the character traits interfaced to generate action on the specific occasion.

\section{iv. Narrow Traits Responses}

Similar conclusions follow from narrow traits responses, which hold that virtues are relatively narrow, finely-individuated dispositions for action. Recall that when motivating a narrow traits response to the situationist challenge, Kamtekar claims honest dispositions qua aversion to stealing or cheating might diverge from honesty qua truth telling. A person might be disposed towards lying, for instance, but not stealing or cheating.

Suppose a legal factfinder is given evidence that the defendant is dishonest. The narrow traits response indicates limitations of this evidence. Firstly, the defendant might manifest some narrow dispositions of dishonesty, but not those relevant to the crime. The prosecutor must adduce evidence of the specific relevant narrow trait. ${ }^{29}$ Psychological science might reveal what the relevant level of generality is for such traits, but the wholesale introduction of a scientific branch into legal procedures faces its own evidentiary burdens. ${ }^{30}$ If people tend to attribute broad global character traits, and erroneously assume conduct stems from these broad traits, then character evidence is systematically distorting and biasing. This is because factfinders overestimate the epistemic significance of broad trait ascriptions for proving conduct. That is, when judging others, our paintbrush is too broad. Finally, even if the defendant possesses the relevant narrow disposition, and this underwrites actional tendencies, different narrow traits may have been operative on the disputed occasion. Legal procedures, recall, adjudicate specific instances, not general behavioral patterns.

Both the competing traits and narrow traits responses to situationism place characterological features-personality traits and virtues - at the center of explanations of conduct. But it does not follow that one can reliably predict or ascertain conduct from those characterological features.

\section{$\underline{\mathrm{v} .}$ Reasons-Centering Responses}

Reasons-centering responses claim that character virtues are dispositions to act on reasons. A person's habits of reasoning help constitute their character, and their character helps determine which reasons they notice, and how they interpret, assess, weigh, and act on those reasons. ${ }^{31}$

Reasons are abundant. A given context can offer a cacophony of competing, multi-faceted, nuanced, interlocking reasons; some are hidden, others are obvious. To determine how or why a person acts, we must often discern their reasons. But this can be extremely difficult. Unlike actions, a person's reasons are unobservable. Indeed we are often mistaken about our own reasons for acting. And it is often impossible to tell what reasons a person found salient or how they interpreted, assessed, and weighed those reasons. Reason-centering responses thereby indicate the relationship between character and conduct is not straightforward or easily uncovered.

Elisabeth Camp (forthcoming) glosses a perspective as "an open-ended disposition to interpret whatever one encounters [...] by noticing, relating, and responding to information in a way that

29 Sometimes adduced evidence will be of the relevant narrow trait, consistently operating across relevantly similar contexts. But in evidence law, being sometimes truth conducive does not suffice to justify admissibility. Thanks to John Greco and Eric Wiland for raising this objection.

30 Feldman 1995; Berger and Solan 2008; Haack (2014).

31 Needless to say, these influences create looping mechanisms. Gardiner (forthcoming-a) describes looping mechanisms among attentional traits, other character traits, and a person's reasons and values. 
intertwines factual assumptions and evaluative commitments" and Jessie Munton (forthcoming) theorizes salience structures, understood as "an ordering of information by accessibility". Perspectives, salience structures, and related posits aim to characterize the interface between a person's environment and their reason-responsive actions by explaining how the person sees their environment: which features are salient to them, for example, and what they overlook. ${ }^{32}$

Munton and Camp do not frame their theories around virtue or other characterological notions, but reasons-centering responses to the situationist critique highlight the importance of virtue theoretic treatments of such phenomena, including a virtue ethics of attention, visual perception, and interpreting environmental stimuli. Various virtue theorists highlight the importance of attentional patterns for virtue, including virtuous attunement in aesthetics and in the ethics of care. ${ }^{33}$ But we urge virtue theories of attention, salience structures, and Campian perspectives. Gardiner (forthcoming) posits that being properly attuned - having the right attentional patterns - is itself a cognitive virtue, for example, and sketches the normative contours of this virtue, for both individuals and collectives. Gardiner (forthcoming) emphasizes that proper attention is a diachronic feature, for example, which helps motivate that proper attunement is a virtue notion.

The confederate in the Good Samaritan experiment intentionally appeared "somewhat ambiguousill-dressed, possibly in need of help, but also possibly drunk or even potentially dangerous" (Darley and Batson 1973: 102). The situation thus does not present a clear-cut case of need and instead suggests conflicting considerations, relating to the traits of beneficence and self-protection. When navigating ambiguous situations, emotions, perspectives, and salience structures help determine which reasons are salient and how they are interpreted. ${ }^{34}$ Given this, a virtue epistemology of attention might reveal the seminarians' actions were responsive to reasons and rooted in stable character traits, yet which reasons they perceived and responded to was influenced by situational and emotional features. ${ }^{35}$ Plausibly when running late the seminarians tend-through adrenaline or self-absorption-to notice reasons concerning self-protection. When unhurried, beneficence-relevant reasons, such as other people's needs, become salient. ${ }^{36}$

Annas (2003:__) writes,

32 Camp (2003) enumerates ideas in the vicinity of perspectives, such as outlook, orientation, ideology, worldview, or standpoint. She focuses on perspectives as modes of interpretation, not merely as attention directors. Munton by contrast focuses on attention.

33 On normative roles of attention, see Murdoch (2003: 16-36), Herman, Brewer (2009), Watzl (2017), and Seigel (ms). Alfano (2013: 76) highlights the importance of attention for virtue in his discussion of the situationist challenge. Gardiner (forthcoming-a) posits virtues and vices of attention.

34 See, for example, Elgin (1999: chapter five) on the epistemology of how emotion steers attention.

35 lack space to develop this here, but similar considerations could explain observed behavior in other situationist experiments. Alfano (2013: 43-45) claims that situationist experiments show that behavior is largely determined by "situational non-reasons" such as ambient noise and odor. But such features can be reconstrued as directing attention, which is itself characterological, reasons-responsive, and determines which situational reasons a person notices and acts on. Perhaps, then, the experiments do not show behavior is determined by non-reasons, but instead show how situations influence reason-responsive behavior. Virtue ethical responses to such experiments should not claim that people are perfectly reasons-responsive; non-reasons have behavioral effects. But virtue ethics can draw on the epistemology of attention, emotions, and interpretations of environment to highlight underappreciated contours of reasons-responsiveness.

36 Chappell and Yetter-Chappell (2016) provide an insightful discussion of how salience of need affects the virtues of beneficence. Gardiner (forthcoming-a) employs this to explain the efficacy of political protests as influencing salience. On virtue and attention, see Herman, Brewer (2003), Murdoch (2003), and Tumulty. 
So far I have not found anyone who takes [the situationist] line of thought [about the Samaritan example] to its logical conclusion, namely [...] to impress on us the importance of good time management.

A virtue ethics of attention and perceptual salience converge on Annas's insightful conclusion.

We have argued that virtue ethical responses to the situationist critique show that character evidence is epistemically onerous. Reliable character ascriptions and character-to-conduct judgmentsespecially specific action determinations-require substantial background evidence and are liable to error. There is consilience between the four families of responses. That is, they provide interlocking and mutually supporting reasons to conclude that character judgments are often abstruse. Theorists leverage situationism to support legal character evidence exclusions rules, such as FRE 404(a). They argue situationism indicates that character evidence, as used in law, is unreliable. Virtue ethical rebuttals to the situationist challenge support the same conclusion. ${ }^{37}$

Indeed it is unsurprising that virtue ethical responses to situationist experiments imply that character evidence is abstruse. This is because such responses must either show the experiments are methodologically inadequate —impugned by failures of design or replication_or show that virtue ethics can countenance the variability of conduct elicited in the experimental conditions. Either heterogeneous conduct is compatible with any given trait or those traits are rare. Either way, it vitiates the epistemic value of character evidence for predicting conduct.

Virtue ethics must comport with the prosaic truth that people can be hard to know. People's behavior can surprise us. We might say of a former friend that "He just wasn't the person I thought he was" and we might learn that - despite her professional attire and habits-Lily lacks an iron. Both examples are recent real-life cases, and this is not incidental: ${ }^{38}$ We earlier sketched thin, one-dimensional fictional cases; such adumbration can illusively suggest the simplicity and reliability of character inferences, but in reality people are nuanced and multi-faceted. We contain multitudes.

\section{Character Evidence in Law and Life}

We conclude by addressing two concerns. Firstly, evidence law permits lots of technical and recondite kinds of evidence — attorneys adduce complex forensic evidence for example_-so the mere evidential burdens and epistemic challenges of character evidence do not suffice for exclusion. Given this, why do the epistemic challenges of character judgments justify an exclusion? Secondly, section one noted that character inferences are ubiquitous in everyday life. Do our arguments against uses of character evidence in law impugn everyday character inferences? Both questions ask why the caliginosity of character, and the resulting obstacles for character judgments, constitute a distinctive problem in legal contexts.

Legal procedures often involve technical, recondite evidence. To navigate this, courts introduce expert witnesses to guide factfinders. Accordingly, experts in the psychology of character could—in theory-

\footnotetext{
37 Sometimes character evidence helps secure more accurate verdicts. But this observation does not undermine a general prohibition. Evidence rules exclude evidence kinds whole cloth, even if they sometimes lead to true beliefs. Similarly, character evidence might be probative-it might generally point towards truth. But it can still nonetheless lead astray, and so be excluded on epistemic grounds - if its epistemic value is systematically overestimated or misunderstood.

38 Gardiner's friend articulated the remark, verbatim, within the last few days. Lily is a pseudonym.
} 
be introduced to explain how conflicting, narrow, developing, and reasons-responsive traits might lead to actions in a given specific situation. The experts could study the defendant's personality carefully to produce a personality profile. ${ }^{39}$ But even if the psychology of personality aspires to one day perform this task reliably, it cannot yet. Research areas, such as fingerprint analysis, must satisfy particular standards before they can be the subject of expert testimony. The Frye standard, which requires a scientific technique to be "sufficiently established to have gained general acceptance" in its field, governed admission in the USA until 1993. It has since been superseded by the more permissive Daubert standard. But neither situationism, nor the virtue ethical rebuttals, offer reason to think that personality experts can provide testimony that is specific enough to help adjudicate a case and yet sufficiently reliable to satisfy the standards for admitting expert witnesses.

Secondly, studies suggest unfavorable character evidence is typically more impactful than favorable character evidence. If, as we suggest, character evidence is unreliable and overestimated, then errors probably disproportionately disadvantage the defendant. That is, they tend towards false convictions rather than false acquittals. Perhaps in ordinary life the cynical pull of character evidence is less problematic, but legal systems aim to avoid false convictions, even if more false acquittals result.

Thirdly, some legal epistemologists maintain that legal procedures do not aim to merely maximize the ratio of true verdicts to false ones. They also aim to secure sensitive verdicts. An affirmative verdict is sensitive to the defendant's guilt iff were the defendant innocent the factfinders would have acquitted. ${ }^{40}$ Sensitivity can diverge from a simple truth ratio. To see why, suppose that unfavorable character evidence is extremely difficult to rebut. Once jurors hear it, they tend towards conviction and the defense struggles to persuade them otherwise. Like poop on a shoe, unfavorable character evidence is hard to shake off. Now suppose that most defendants are guilty. If unfavorable character evidence is admissible, this might foreseeably increase the number of true convictions and reduce the false acquittal rate. This is because it increases inculpatory evidence against all defendants and most defendants are guilty. But it leads to insensitive verdicts: Were those defendants innocent, the factfinders would nonetheless find them guilty.

But, fourthly, the same holds for innocent defendants. The innocent face an elevated risk of false conviction because character evidence is hard to dispute; the poop sticks. Regardless of whether sensitivity has legal value, legal systems aim to avoid admitting kinds of inculpatory evidence that innocent defendants could not effectively dispute. Plausibly if innocent defendants could not rebut the kind of evidence used against them, the false conviction is thereby rendered unjust. Plausibly character evidence exhibits these features. It secures more convictions overall, and defendants tend to be guilty, so it increases the overall rate of true verdicts. But, because it is difficult to refute, it leads to insensitive verdicts and unjust false convictions.

We can distinguish two epistemic features of inculpatory character evidence. It is 'condemnatory' if it renders factfinders highly prone to convict. Perhaps they overestimate its probative force or underestimate the significance of false conviction because the defendant committed prior crimes or is deemed ignoble. Evidence is condemnatory if, unless rebutted, conviction is extremely likely. Confessions are condemnatory, for example. Secondly, evidence is 'hard to shake' if the evidence is difficult to rebut. These two properties can come apart. Condemnatory evidence that one can rebut is like food on the floor. It's a problem until rectified, but it is typically easy to clean up. Evidence that

39 See Méndez (1996) and Sonenshein (2011).

40 On the legal value of sensitivity, see Enoch et al (2012), Gardiner (2018), and Gardiner and Zaharatos (ms). 
is hard to shake but not condemnatory is like chalk dust around a blackboard. The chalk is hard to clean up, but typically no botheration. Evidence can be neither: The false claim that the defendant is Canadian is like books strewn around a nightstand. Unperturbing even if not fixed and easy to remedy. But character evidence might resemble red wine on a white rug: Condemnatory and hard to shed. That is a problem.

One might wonder whether factfinders can simply downgrade character evidence, to reflect its abstrusity. Suppose an attorney introduces fingerprint evidence and an opposing attorney casts doubt on it. The legal system operates on the assumption that factfinders can accordingly downgrade the evidence. They originally believed it was highly compelling, but now they find it less so. Similarly, confidence in an entire species of evidence, such as handwriting authentication, could be downgraded. Could a similar corrective be made for character evidence?

There is reason for skepticism. If factfinders hear a pertinent character assassination and are subsequently told to wholly disregard it, realistically they would be unable to epistemically quarantine it. The character evidence would remain epistemically efficacious. The poop sticks. For similar reasons, we suspect it is hard to cognitively downgrade character evidence. Even if factfinders can do this with unfamiliar abstruse evidence, such as fingerprint analysis, they would struggle to do so for character evidence. People usually consider themselves good judges of character, relying on character evidence is ingrained, and character inferences are deemed broadly reliable. And so factfinders will overestimate its probative force and be unwilling or unable to downgrade it.

This leads to the second question: Does our discussion of the epistemic weaknesses of character evidence call ordinary practices into doubt? If character inferences are widespread, and yet recondite and unreliable in unappreciated ways, are everyday practices mistaken? ${ }^{41}$

In response, we briefly sketch ways that everyday uses of character evidence tend to differ from legal ones. We thereby suggest that well-grounded, epistemically responsible character judgments do not resemble the ones prohibited by evidentiary rules like FRE 404(a). This section is gestural; we lack space to fully develop the claims.

Recall that FRE 404(a) prohibits a specific kind of character judgment: specific action determinations. That is, inferences from character ascription to discovery-mode judgments about specific instances of past unobserved conduct. Somebody keyed the car and the factfinder must decide whether Laurie did it; Dan drove home, the court must decide whether he was drunk. And in legal contexts, the stakes are high and the verdicts have finality; they are not easily revised.

Everyday character judgments, by contrast, are often in the coherence-assessing mode. ${ }^{42}$ Rather than ascertaining facts, we think about whether conduct and traits fit with other claims we believe about a person. Everyday character judgments are often broad-brush character ascriptions, rather than character-to-conduct inferences. And when they concern conduct, they are about general patterns of behavior rather than specific unobserved instances. When they concern specific instances, typically we learn of past conduct and-in the coherence mode_-judge whether "that fits". We might think

41 Thanks to Catherine Elgin and P. D. Magnus for asking this question.

42 We simply characterize how typical everyday character inferences can differ from legally prohibited ones. We do not characterize all everyday character judgments. Philosophy training tends towards thinking of counterinstances, even if abnormal, but here we urge focusing on normal everyday cases. 
"I'm not surprised that Sam was in a bar fight, given what I know of him". Part of why such assessments can be well-grounded is that a person's character influences which situations a person tends to be in. Sam's character leads him to seedy bars, which are environments that render bar fights more likely. But outside of legal contexts, we seldom use character judgments to determine whether Sam will (or did) fight on a specific given occasion. Specific action determinations in non-legal contexts occur, but - we aver-they are less common than other species of character inference, and less common than usually appreciated.

In ordinary life we tend to know the subjects well and have ample firsthand experience. Legal factfinders, by contrast, have constrained information in narrow, artificial contexts. Where the evidence is limited in ordinary life, character judgments are typically low stakes-no one goes to prison-and are readily revisable. They are working hypotheses about personalities and actions. Characteristic of the coherence-mode, such assessments are often in reflective equilibrium with other assessments and adapt to accommodate various interpretations. One thinks "Tilly is considerate, so she probably selects thoughtful gifts". On learning she gave a mezzaluna one might adjust the assessment of Tilly, or mezzalunas, or the relationship between thoughtfulness and gift giving. Perhaps gifts are a capitalist trap and not reflective of good character. Plausibly one simply never reflects on the assessments; it doesn't really matter.

This brief sketch suggests how character inferences can be epistemically responsible in everyday contexts, yet unreliable in legal contexts. We thus aim to reconcile everyday practices with our epistemological case for legal character evidence exclusion rules. Some everyday uses of character evidence will be of the epistemically dubious kind—specific action determinations—and should be viewed with caution. And some, perhaps many, mundane non-legal uses of character evidence are epistemically irresponsible. Character ascriptions might often be based on paltry evidence, for example, or be resistant to counterevidence. One major distinction between law and everyday life is simply that inference patterns cannot be formally excluded in typical everyday contexts, even if they are epistemically atrocious. We urge epistemic humility about the limits of character judgments, in law and in life.

Thus we hope to show how mundane character inferences can be reasonable and commonplace. But the very ubiquity of character judgments can be illusive. It creates the misapprehension that otherdissimilar-uses of character evidence are also epistemically legitimate, such as those proscribed by FRE 404(a).

Since character evidence is less reliable than is commonly appreciated, and its epistemic value is overestimated, there are epistemic grounds for excluding character evidence from legal proceedings. Far from being saddled with endorsing the use of character evidence in legal factfinding, virtue ethicists should support legal character evidence prohibitions. Virtue ethical rebuttals to situationism themselves show why. ${ }^{43}$

43 Important questions remain about a virtue ethical treatment of currently permitted uses of character evidence in law, such as for sentencing, parole, and witness impeachment as permitted by FRE 607, 608, and 609. And in the US, FRE 404(b) (2) permits the use of prior conduct to prove motive, opportunity, intent, preparation, plan, knowledge, identity, absence of mistake, or lack of accident. 


\section{Acknowledgements}

This research benefitted from discussions at the Social Epistemology Network's Social (Distance) Epistemology workshop and the fall 2019 Social Epistemology Seminar at the University of Tennessee. Many thanks to Catherine Elgin, P. D. Magnus, Clerk Shaw, Eric Wiland for particularly helpful discussion. Special thanks to Michael Ebling, Isabelle Farineau, Jon Garthoff, Paige Greene, Linh Mac, and Jodi Smith for comments on earlier drafts. This research was supported by a Graduate Research Award from the University of Tennessee Graduate School and by an ACLS Fellowship from the American Council of Learned Societies.

\section{Bibliography}

Alfano, M. 2012. Expanding the situationist challenge to responsibilist virtue epistemology. Philosophical Quarterly 62(247). 223-249.

- 2013. Character as Moral Fiction. New York: Cambridge University Press.

- 2018. A plague on both your houses: Virtue ethics after situationism and repligate. Teoria. Allport, Gordon. 1937. Personality: A Psychological Interpretation. New York, NY: Henry Holt.

Annas., J. 2003. Virtue ethics and social psychology. A Priori 2. 20-59

Aristotle. 1999. Nicomachean Ethics (T. Irwin Trans.). Indianapolis: Hackett Publishing Co.

Armour, J. D. 1994. Race ipsa loquitor: of reasonable racists, intelligent bayesians, and involuntary negrophobes. Stanford Law Review, 46(4), 781-816.

Barron, R. 1997. The sweet smell of... helping: effects of pleasant ambient fragrance on prosocial behavior in shopping malls. Personality and Social Psychology Bulletin 23. 489-503.

Berger, M. A, \& L. M Solan (eds.). 2008. Symposium: A cross-disciplinary look at scientific truth: What's the law got to do with it? Brooklyn Law Review 73(3) 847-1251.

Blass, T. 1999. The Milgram paradigm after 35 years: Some things we now know about obedience to authority. Journal of Applied Social Psychology 29, 955-978.

Brewer, T. 2009. The Retrieval of Ethics, Oxford UP.

Cattell, R. B. 1950. Personality: A Systematic Theoretical and Factual Study. New York: McGraw-Hill.

Chappell, R. Y. \& H. Yetter-Chappell. 2016. Virtue and Salience. Australasian Journal of Philosophy 93(3). 449-463.

Cohen, S. 1978. Environmental load and the allocation of attention. Advances in Environmental Psychology vol. 1 (Baum, Singer, and Valins eds). Hillsdale, NJ: Erlbaum.

Darley, J. \& Batson, C. D. 1973. From Jerusalem to Jericho: A study of situational disposition variables in helping behavior. Journal of Personality and Social Psychology, 27(1), 100-108.

Doris, John. 2002. Lack of Character: Personality and Moral Behavior, Cambridge: Cambridge University Press.

Eggleston, R. 1983. Evidence, Probability and Proof. London: Weidenfeld \& Nicolson.

Enoch, D, L. Spectre, \& T. Fischer. 2012. Statistical Evidence, Sensitivity, and the Legal Value of Knowledge. Philosopby and Public Affairs 40(3). 197-224.

Elgin, C. 1999. Considered Judgment. Princeton University Press.

Eysenck, H. J. 1953. The Structure of Human Personality. London: Methuen Publishers.

Feldman, H. L. 1995. Science and Uncertainty in mass exposure litigation. Texas Law Review 74(1). 1 48. 
Fleeson, W. and Noftle, E. E. 2009. The end of the person-situation debate: an emerging synthesis in the answer to the consistency question. Social and Personality Psychology Compass, 2(4):16671684.

Gardiner, G. 2012. Understanding, Integration, and Epistemic Value. Acta Analytica 27(2). 163-181.

- 2018. 'Legal Burdens of Proof and Statistical Evidence' Routledge Handbook of Applied Epistemology, eds. David Coady and James Chase. Routledge, 171-95.

—. 2019. 'Legal Epistemology' Oxford Bibliographies: Philosophy, ed. Duncan Pritchard. OUP. - Forthcoming-a. Attunement: On the cognitive virtues of attention. Social Virtue Epistemology (Alfano, Klein, and Ridder eds.).

Gardiner G. and Zaharatos, B. ms. 'The Safe, the Sensitive, and the Severely Tested: A Unified Account'.

Goldman, A. 1999. Knowledge in a Social World. New York, NY: Oxford University Press.

Haack, Susan. 2014. Evidence Matters: Science, Proof, and Truth in the Law. Cambridge University Press.

Harman, G. 1999. Moral philosophy meets social psychology: Virtue ethics and the fundamental attribution error. Proceedings of the Aristotelian Society, 99, 315-331.

- 2000. The Nonexistence of Character Traits. Proceedings from the Aristotelian Society, 100, 223-226.

Hartshorne H. \& M. S, May. 1928. Studies in the nature of character: Studies in deceit. New York: Macmillan.

Kamtekar, R. 2004. Situationism and virtue ethics on the content of our character. Ethics, 114(3), 458-491.

Kaplan, J. 1968. Decision theory and the factfinding process. Stanford Law Review 20(6). 1065-1092.

Laudan, L. 2016. Truth, error, and criminal law: an essay in legal epistemology. New York: Cambridge University Press.

Lupfer, M., R. Cohen, J. L. Bernard, D. Smalley. 1986. Presenting favorable and unfavorable character evidence to juries. Law and Psychology Review 10. 59-71.

Matthews, K. E. \& L. K. Cannon. 1975. Environmental noise level as a determinant of helping behavior. Journal of Personality and Social Psychology 32. 571-577.

Melilli, K. J. 1998. The character evidence rule revisited. Brigham Young University Law Review (4). 1547-1630.

Méndez, M. A. 1996. The law of evidence and the search for a stable personality. Emory Law Journal, 45, 221-238.

. 1998. Character evidence reconsidered: "People do not seem to be predictable characters". Hastings Law Review 46(3), 871-894.

Milgram, S. 1963. Behavioral study of obedience. The Journal of Abnormal and Social Psychology 67(4), 371-378.

. 1974. Obedience to Authority: An Experimental Approach. New York: Harper and Row Publishers.

Miller, C. 2003. Social psychology and virtue ethics. Journal of Ethics, 7(4), 365-392.

- 2013. Moral character: An empirical theory. New York, NY: Oxford University Press. - 2020. Empirical Approaches to Character. Stanford Encyclopedia of Philosophy.

https://plato.stanford.edu/entries/moral-character-empirical/. Accessed 2 September, 2020.

Mischel, W. 1968. Personality and assessment. New York: Wiley. 
Mischel, W., \& Y. Shoda. 1995. A cognitive-affective system theory of personality: reconceptualizing situations, dispositions, dynamics, and invariance in personality structure. Psychological Review 102. 246-268.

Munton, J. Forthcoming. Prejudice as the misattribution of salience. Analytic Philosophy.

Murdoch, I. 2003. The Sovereignty of Good. New York: Routledge.

Plato 1966. Phaedo. Trans. Harold North Fowler. London, UK: Harvard University Press.

Ross, L. \& R. E. Nisbett. 1991. The Person and the Situation. New York: Harper and Row Publishers.

Sanchirico, C. W. 2001. Character Evidence and the Object of Trial. Columbia Law Review, 101(6), 1227-1311.

Seneca. 1917. Epistles, Volume I: Epistles 1-65. Translated by Richard M. Gummere. Loeb Classical Library 75. Cambridge, MA: Harvard University Press.

Siegel, Susanna (ms) "Are there norms of salience?"

Sonenshein, D. A. 2011. The misuse of rule 404(b) on the issue of intent in the Federal Courts. Creighton Law Review 45, 215-276.

Sreenivasan, G. 2002. Errors about errors: Virtue theory and trait attribution. Mind 111(441), 47-86.

Thompson, M. K. 2015. Blackness as character evidence. Michigan Journal of Race \& Law, 20, 320347.

Tillers, P. 1998. What is wrong with character evidence? Hastings Law Journal 49(3). 781-834.

U. S. Congress. 1982. United States Code: Federal Rules of Evidence.

Uviller, H. R. 1982. Evidence of character to prove conduct: Illusion, illogic, and injustice in the courtroom. University of Pennsylvania Law Review, 130, 845-891.

Watzl, S. 2017. Structuring Mind: The Nature of Attention and How it Shapes Consciousness. New York: Oxford University Press.

Westra, E. 2020. In defense of ordinary character judgment. Erkenntnis,

Zhong, C.-B, V. Bohns, \& F. Gino. 2010. Good lamps are the best police: darkness increases dishonesty and self-interested behavior. Psychological Science 21(3). 311-314. 